\title{
Transforming television drama through dubbing and subtitling: sex and the cities
}

Article

Accepted Version

Knox, S. and Adamou, C. (2011) Transforming television drama through dubbing and subtitling: sex and the cities. Critical Studies in Television, 6 (1). pp. 1-21. ISSN 1749-6020 Available at https://centaur.reading.ac.uk/17813/

It is advisable to refer to the publisher's version if you intend to cite from the work. See Guidance on citing.

Published version at: http://www.manchesteruniversitypress.co.uk/cgi-bin/scribe?showinfo=ip028

Publisher: Manchester University Press

All outputs in CentAUR are protected by Intellectual Property Rights law, including copyright law. Copyright and IPR is retained by the creators or other copyright holders. Terms and conditions for use of this material are defined in the End User Agreement.

\section{www.reading.ac.uk/centaur}

\section{CentAUR}

Central Archive at the University of Reading

Reading's research outputs online 
Transforming Television Drama through Dubbing and Subtitling: Sex and the Cities Christina Adamou and Simone Knox

The translation practices of dubbing and subtitling, according to Richard Kilborn, are more often than not held in disdain, with dubbing the more despised form. ${ }^{\mathrm{i}}$ However, it is worth pointing out that this negative attitude is more widespread in countries and television cultures that make less use of these practices, such as the United Kingdom. Both dubbing and subtitling are often conceived of in terms of necessity and practicality: the need for strict adherence to lip-synchronisation, the need for compatibility of source voice and dubbing voice, or the need to use no more than approximately 40 characters on screen in subtitling, ${ }^{\text {ii }}$ to allow enough time for the viewer to read the words. A commonly held assumption is that dubbing and subtitling can, at best, produce a translated equivalent - if not equivalence of information, then equivalence of effect - to the source language version. ${ }^{\text {iii }}$ It is also worth noting that inherent in this idea of equivalence are problematic assumptions that the text has a single 'correct' meaning, which can be 'correctly' read by viewers (or at least 'competent' ones), and, somewhat contradictorily, that textual identity is stable. (We say 'contradictorily,' because the notion of equivalence suggests that there is a stable source text to which an equivalent can be given, when the very process of constructing an equivalent - another version -implies that textual identity is not stable.) In that view, complete transparency of the translated text is desired. If the two practices stray from this equivalence, charges of loss and lack of fidelity, even falsity, are likely to be made.

However, while there is often a strong and, in many ways, 'obvious' correspondence between the source and target language versions, what this essay argues is that there is no such thing as (total) equivalence: the two practices do not 
simply involve 'a recreation of the original text'; $;$ iv they instead need to be understood as transformative practices that problematise the very notion of a single text, in ways that move beyond loss, lack of fidelity and falsity. Not only does each (source and target) language bring its own characteristics, aesthetics and texture to the text, but each version is also created for a particular target market and specific national (television) culture. This essay emphasises the importance of choices made within different industrial/institutional and production contexts; and it draw on, as well as explicitly connects with, John Gibbs' work on filmmakers' choices. As Gibbs writes: Making a film involves a myriad of choices. Every frame, every cut, every element of performance and every note of the soundtrack results from pursuing one option and refusing many others. When investigating a film, a valuable approach is to identify a decision, or a group of decisions, and ask 'what is gained by doing it this way?' [...] To think in such terms is to consider the crux of the artistic process: the relationship between decisions taken and a work's meanings.

With the translation of audiovisual texts, there is never one possibility for translating a word, phrase, sentence, nuance, mood or tone; the importance of necessity, practicality and other constraints notwithstanding, a number of choices and decisions are made with every version that is created. These choices have particular effects on the text, structuring it differently and creating distinct meanings and discrete connotations. Approaching audio-visual translation from this point of view shifts the argument away from deficiency and falseness, and indeed the very notion of a fixed text, toward a closer textual engagement with these choices and, therefore, with different versions rooted in distinct national contexts. 
To this end, the essay investigates some of the choices made in the audiovisual translation of the popular and critically acclaimed US comedy-drama television series, Sex and the City (1998-2004), for German and Greek television; and it examines how this US text has been transformed through dubbing and subtitling. Sex and the City is an interesting case study, because it is an HBO product firmly embedded in the company's original programming philosophy, which is based on quality. The show's transition from a premiere, pay-per-view US cable channel to free-to-air channels in non-Anglophone countries highlights the important shaping effects of institutional contexts and audio-visual translation, as well as the links between them. Raising the very notion of 'the text' as central, Sex and the City's transnational travels also add to existing Sex and the City scholarship that notes and/or contests its edginess, and in particular its gendered representations, which, in turn, informs this current project.

By focusing on dubbing and subtitling, this essay aims to profile such practices and the implications for the discipline of television studies. Resurgent interest in international flows and exchanges of television has challenged earlier media imperialism models (such as Schiller's) ${ }^{\mathrm{vi}}$ and increased scholarly awareness of trans-national broadcasting contexts and processes. That said, not enough attention has been paid to the translation of audio-visual works for non-English language importing television markets. While Germany traditionally dubs, Greece usually prefers to subtitle its imports: two European countries, two different practices, which, in turn, offers a unique opportunity to explore what translation reveals about the complex issues of institutional, cultural and textual identity. 


\section{Textual Aesthetics and Institutional Contexts:}

\section{Language and Translation Practices}

To elucidate on choices made in dubbing and subtitling, and the noticeable affect they have upon the text, the following analysis of the opening minutes of the Sex and the City episode 'The Awful Truth' (2:2) proves illuminating. Particular attention is paid the second sequence, when Carrie Bradshaw (Sarah Jessica Parker) visits SusanSharon (Molly Price), and, having inadvertently woken up her friend's moody husband Richard (Neal Jones), leaves as the couple start to fight. Striking, especially given how Sex and the City (particularly in the early seasons) was noted for, as Astrid Henry describes, 'its frank discussion of female sexuality and its refreshing representation of the lives of contemporary women', ${ }^{\text {vii }}$ is how the German and Greek versions convey a lesser sense of aggression between the sexes. This is partly because of a reduction in bad language - referred to here specifically as rude language used in a non-sexual sense - in the German and Greek versions, for a number of institutional reasons that will be unpicked. For example, in the US version the husband complains about the 'fucking noise' that woke him up. This is dubbed into German as 'scheiß Krach', which back-translates as 'shit racket'; whilst in the Greek subtitles, 'fucking noise' becomes ' $\theta$ ópvßos' (thorivos), which simply means 'noise'. In his directive for Carrie to 'get the fuck out of my house', 'the fuck' - stressed by Jones's intonation in the source text - is changed in the German dub to 'verpiss dich' ('piss off'). The word choice remains coarse, but nevertheless is less offensive than the emphasised fourletter word in the source text. In the Greek version, the word is omitted completely.

These particular choices are not too surprising for a number of reasons. In Germany, for example, Sex and the City was broadcast on commercial channel ProSieben in a primetime evening slot. Yet these dubbing choices become more 
noticeable when considering that the primetime slot on ProSieben does feature the series' sexually explicit content.

Sex and the City was broadcast on Greek commercial television in a late-night slot, with some swear words kept in. Conventional practice dictates that Greek subtitling omit expletives not central to textual meaning, and a number (including 'hell' and the afore-mentioned 'fuck') have been cut, and not for obvious reasons like economy of space. Moreover, the US source audio remains, and thus such exclusions are potentially noticeable to viewers conversant with the English language. The reduction of bad language in the subtitles mellows Richard's aggressiveness towards both his wife and Carrie, and as a result, lessens the sense of tension between the sexes.

Bad language in Sex and the City is often understood as part of HBO's brand identity: as a deregulated, advertiser-free subscription channel, HBO seeks (and arguably needs $)^{\text {viii }}$ to distinguish itself from network television in and through its 'edgy' programming, noted for pushing boundaries and breaking taboos. While the presence of US drama series has been important to the brand identity of both ProSieben and Filmnet/Nova (the Greek subscription channel on which Sex and the City was first broadcast in Greece in 2001), swearing becomes arguably less essential to the German and Greek target texts, as ProSieben and Filmnet/Nova are not invested in producing a similar notion of distinctiveness. ${ }^{\text {ix }}$ This is because ProSieben is not as exclusive as the subscription-based HBO, and the channel identity of Filmnet/Nova is not based on cutting-edge television drama, but films and sports.

Following initial ratings success in primetime, ProSieben decided in 2006, to move Sex and the City to an earlier slot in the schedule. With the promotional tagline 'Sex um Sechs' ('Sex at Six’), the channel stripped the repeated episodes in a 
weekday 6pm slot. Such a move promoted complaints about such material being shown at a time when younger viewers might be watching. ${ }^{\mathrm{x}}$ But with the earlier time schedule came cuts to the explicit content and language- not so much 'Sex um Sechs', after all. It was a decision that also frustrated Sex and the City fans, who felt that the series had been inappropriately used to fill a scheduling gap left by the failure of telenovella Lotta in Love (2006). ProSieben's scheduling strategy was stopped after only 18 broadcast episodes. The earlier scheduling did not only affect the translation practices, but was also part of a broader transformative practice that altered the identity of the series, attempting (and failing) to turn it into a family viewing programme.

Explicit content also impacted on the scheduling of the series in Greece. First broadcast in 2001 on subscription channel Filmnet/Nova, Sex and the City screened on the free-to-air private channel Alter in 2002, before moving to another free-to-air channel, Alpha, in 2008. Filmnet/Nova and Alpha aired Sex and the City without cutting the audio-visual source material: Alpha broadcast uncut repeats in a late-night scheduling slot, while subscription channel Filmnet/Nova broadcast new episodes at 9pm, with the assumption that adults choose whether to subscribe and parents control the viewing of subscription television. Free-to-air Alter broadcast a cut version that omitted some nudity scenes at around $10.15 \mathrm{pm}$ initially; but in 2004 , the broadcaster had to comply with the recommendation from the Greek National Council for Radio and Television's (NCRTV/E $\mathrm{P}$ ) that they broadcast it only after $11 \mathrm{pm} .^{\mathrm{xi}}$ This decision was based on the potential of sexually explicit dialogue to damage the 'spiritual and moral growth of the underage public'. xii Given that NCRTV/E $\Sigma$ P referred to subtitled dialogue, it suggests the importance placed on subtitles within regulatory discourses. 
Considering the complexity of Sex and the City's Greek broadcasting context, the absence of certain offensive words, such as 'fuck' (used in a non-sexual context), must be understood in relation not only to conventions of Greek subtitling practice, but also to the fact that the presence of such words - which would maximise the series' textual distinctiveness - had no benefit for the three channels. With a different institutional/industrial context to $\mathrm{HBO}$, the Greek channels would risk regulatory censure. Maximising the text's distinctiveness for the purposes of channel-brand distinction was a pointless risk, especially given the lack of exclusivity over the series. (Only being one year ahead, Filmnet/Nova had merely temporal exclusivity.) Evidently, what is essential, or rather what is deemed essential to the text, is deeply implicated in issues of broadcasting context and channel identity. ${ }^{\text {xiii }}$

\section{Textual Aesthetics and Institutional Contexts: Language and Gender}

The sense of aggression between the sexes is further reduced through other decisions in the audio-visual translation. In the source text, when Carrie leaves the couple's apartment, her parting comment to Richard is 'Good night, Grumpy'. For 'grumpy',

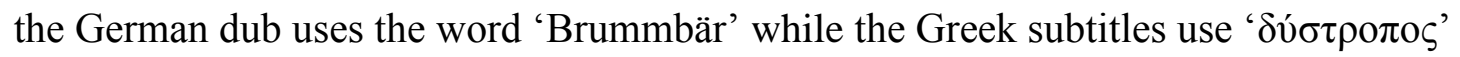
('dystropos'). These are two interesting word choices: 'grumpy' is used to comment on the husband's foul mood, subtly reinforced by Neal Jones's short stature and his wearing of a red robe, which in turn evokes a reference to one of Snow White's seven dwarfs with connotations of emasculation and ridicule. Whilst 'Brummbär' is the German name for the dwarf Grumpy and used to indicate someone - normally, a man - in a bad mood, the word does carry connotations of bear-like masculinity and can be used as an affectionate nickname. It is therefore certainly less mocking and more conciliatory than the US use of 'grumpy'. (It is worth noting that the German dub here 
chose to translate 'grumpy' via the visual reference to Snow White's seven dwarfs, when other choices, such as 'Griesgram', 'Miesepeter' or 'Brummkopf', could have been used.)

However, the dwarfs in the Greek version of Snow White do not have individual names: the chosen ' $\delta$ $\sigma \tau \rho o \pi \circ \varsigma$ ' ('dystropos’) means cantankerous, wayward, surly, recalcitrant. But it is also a quaint term, which seems more like a polite accusation, or an expression from a literary text, rather than a form of mockery. It would have been possible, for instance, to use the word ' $\gamma \kappa \rho t v i \alpha ́ \rho \eta \varsigma '$ ('griniaris'), which translates as 'nagger'; ' $\varphi \omega v \alpha \kappa \lambda \alpha ́ \varsigma^{\prime}$ ('fonaklas'), meaning 'loudmouth'; or even

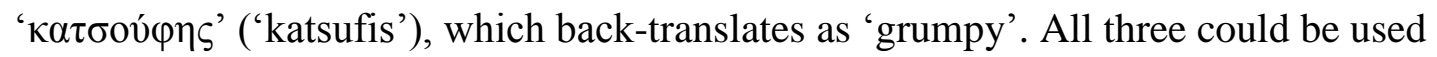
more easily in an everyday context to tease someone; the choice made in the subtitling, however, pushes the translated text in a different direction.

In both versions, the shift in the use of bad language for a programme that is noted for its explicit content significantly alters the programme's ideology. Deborah Jermyn notes that the 'unruly women' in Sex and the City transgress gender boundaries and acquire 'masculine' characteristics, both by exploring their sexuality and by using explicit language and swearing. ${ }^{\text {xiv }}$ The condensation and alteration of dialogue shifts the European translations away from the provocative quality of the source text, and toward a more regressive possibility concerned with reconciliation of the sexes. However, the ideological position of the target-language versions is rendered more complex by further choices concerning the female protagonist(s): both the German dub and the Greek subtitles use explicit sexual references when these are employed in the source text (e.g. the word 'cock' is translated into explicit slang terms in German/Greek later in this episode). Whilst this enables the protagonists to express 
their sexuality more freely, it only makes the reduction of the number of non-sexually explicit swear-words more conspicuous.

Moreover, the German Sex and the City at times confers a greater degree of agency and sexual prowess on its protagonist. For example, in 'They Shoot Single People, Don't They?' (2: 4), Carrie states in the source text that she wants to 'meet cute guys', but in the German dub she says: 'Ich will süße Typen aufreißen.’ This translates as, 'I want to chat up [literally: rip open] cute guys', which implies more sexual agency (and again, other choices, such as 'treffen' or 'kennen lernen' could have been possible).

The Greek Sex and the City, on the other hand, does not necessarily give the protagonist more sexual agency. It instead makes a different choice that, albeit partially grounded in practical imperatives, has a particular effect on the ideology of the text. At the end of the chosen extract from 'The Awful Truth', Carrie's reflective voice-over and the arguing Susan-Sharon and Richard are heard simultaneously. Sex and the City frequently features both diegetic voices (characters' dialogue) and nondiegetic voices (Carrie's voice-over) speaking at the same time. Such a cacophony poses a significant challenge to the writer(s) of subtitles. As Frederic Chaume describes,

when three or more characters speak simultaneously, the translator can only represent a maximum of two characters in each subtitle (a single line for each character). In these cases the selection approach can be to choose the speech of the person or persons nearest to the camera (and hence the spectator), given that they are probably placed there for a reason (a motivated choice) and that their position has to do with the relevance of what they are narrating. ${ }^{\mathrm{xv}}$ 
The Greek translation chooses to subtitle Carrie's voice-over rather than the warring couple. Despite the fact that Carrie has physically left the scene, it is the visually and audibly fighting couple that is rendered absent. The subtitles do not underline visual choices but rather acknowledge and highlight the importance of Carrie's voice-over for the series. As Jonathan Bignell notes, the voice-over links the series to its source, Candace Bushnell's autobiographical newspaper feature column, as well as lifestyle magazine writing. ${ }^{\text {xvi }}$ Joanna di Mattia further claims that, with the heroine on a romantic quest, the female voice-over lends a fairytale quality to the series. ${ }^{\text {xvii }}$ Privileging Carrie's reaction (over the warring couple) in this translated, transnational context reveals how the Greek subtitled version emphasises the female protagonist's voice and her reflective thinking as textually paramount. To this end, so-called practical restraints can actually have the effect of underling the text's privileging of the female gender in general, and of Carrie Bradshaw in particular.

\section{Textual Aesthetics and (Inter)National identity}

An issue related to textual aesthetics and the afore-mentioned question of the audience's linguistic knowledge of English is the 'Americanness', or US specificity, of Sex and the City. Both European versions are strongly marked by a sense of Americanness; the subtitled version, to some extent, inevitably so, because of the source audio; and the dubbed version, quite deliberately so, as it retains numerous references to English as a language as well as to US culture. In the extract, a pun develops around the birthday gift (an expensive cashmere scarf) Susan-Sharon gives to Carrie; she is delighted with the present, exclaiming, 'It's a cashmere-acle!', before asking if she could return it as she needs the cash. Susan-Sharon readily agrees, saying, 'Why do you think they call it cash-mere.' This word play arguably poses a 
challenge for translation. The Greek subtitles opt for non-equivalent replacements:

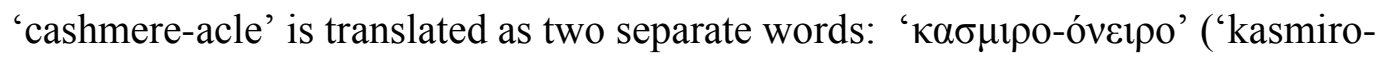
oniro', 'cashmere-dream'), and the phrase, 'Why do you think they call it cash-mere'

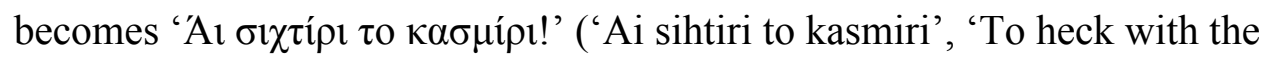
cashmere'), which rhymes in Greek, thus sidestepping any difficulties with translation. Similarly, Greek subtitling regularly omits, changes or generalises extralinguistic cultural references (ECRs), defined as 'expressions that refer to entities outside language, such as names of people, places, institutions, food, customs, etc., which a person may not know, even if s/he knows the language in question., ${ }^{\text {xviii }}$

For example, in the same episode, the reference to Miranda Hobbs' (played by Cynthia Nixon) sex partner 'spring-roll guy' is translated as ' $\sigma \pi \alpha v \alpha \kappa о \pi \imath \tau \alpha \kappa \iota \alpha$ ' ('spanakopitakia', 'spanakopita guy', 'spinach-pie guy'). The choice of 'spanakopita', a dish specific to Greek cuisine and thus carrying very Greek connotations, is surprising, as 'spring rolls' are not a monocultural ECR 'virtually unknown to the TT [target text] audience', ${ }^{\text {xix }}$ but a fairly transcultural ECR that should be accessible to the presumed Greek audience for Sex and the City. Indeed, the two ECRs in question are hardly interchangeable, yet the choice made presumes a degree of 'cultural interchangeability' to highlight the humour in the text; ${ }^{\mathrm{xx}}$ the contemporary urbanlifestyle signifier of spring rolls is subsumed by spanakopita's connotations of traditional home-cooked food that are certainly at odds with the trendiness of Sex and the City. This substitution may produce a sense of familiarity for Greek viewers, but, as it is unlikely to be used by US characters, it may actually cause a credibility gap. In other words, it may problematise the 'tacit agreement $[\ldots]$ between the subtitler and the viewers that the subtitles are the dialogue, that what you read is actually what people say'. ${ }^{x i}$ Seeing as it is more common in Greek subtitling to generalise when 
translating ECRs, the Greek version seeks to domesticate Sex and the City through such a target culture-specific reference, keen to balance the inevitable Americanness of the source text.

Conceptually speaking, there is double movement here: just as the Greek subtitles seek to balance Sex and the City's inevitable Americanness, the German dub seeks to retain it as much as possible. For example, it retains the pun 'cash' and 'cashmere' as far as it can: 'It's a cashmere-acle' becomes 'ein richtiges Kaschmirakel' ('a real cashmere-acle') -the pun maintained as it works with the German words 'Kaschmir' and 'Mirakel'. The exchange between Carrie and Susan-Sharon is thus translated as follows:

Carrie: $\quad$ Ich brauche Cash eigentlich dringender. (I actually need the cash more.)

Susan-Sharon: Ach, wieso nicht. Das Zeug heißt ja auch Cash-mere! (Oh, why not. The stuff is called cash-mere after all!')

This is interesting, because the dubbed version uses the English word 'cash' (instead of the more common, 'Bargeld', or 'Bares'), so that it can retain the 'cash-mere' pun, shifting from 'Kaschmir' to 'cashmere' and expecting the audience to follow. Whilst this can be explained by the difficulty of finding suitable replacements, the dubbing overcomes such problems on a number of occasions through choosing non-equivalent replacements. ${ }^{\text {xii }}$ The motivation for doing so here may be less to do with necessity, than with the target text choosing to retain US words and references. Indeed, the German version is peppered with references to the English language and US culture, including ones likely to be familiar to German audiences (for example, 'freak', 'drink', 'broker', 'downtown') and ones much less likely to be familiar to German audiences, ${ }^{\text {xiii }}$ as well as English pronunciations of, for example, New York street 
names, that could be pronounced in a German way. In contrast to the Greek subtitling, the German dubbing works to retain the Americanness of the text, when this Americanness seems much less inevitable for the dubbed version.

This double movement suggests something about the target audiences and viewing experiences offered by the different translated texts. The usual assumption is that Sex and the City's key demographic consists of educated, young Caucasian female viewers, but this can be unpacked further: the absence of references to US culture and the English language in the subtitles (through omission and substitution for references to Greek culture) creates the possibility of different viewing experiences and audience positions. Viewers conversant with English can pick up these US-centric references in the source audio - indeed, it must be a plausible expectation that a proportion of the Greek audience can interpret the source dialogue - while those less conversant or opting for a more relaxed viewing experience may not pick them up. Thus, the degree of Americanness of the text ultimately depends on viewer knowledge and interest - or lack of these - in US culture and English language.

In the German version, the frequent inclusion of US references also creates the possibility of different viewing experiences and audience positions; only here the expectation is that viewers will be able to 'get' these more inescapable references, at the risk of missing out on the 'fullness' of the text. This risks the exclusion of viewers less conversant with US language and culture, but offers a sense of inclusion and privilege for those viewers with the required cultural capital. The pronounced Americanness of the German Sex and the City does not aim to minimise the text's 'cultural discount', a concept defined by Colin Hoskins and Rolf Mirus as follows: 'A particular programme rooted in one culture, and thus attractive in that environment, 
will have a diminished appeal elsewhere as viewers find it difficult to identify with the style, values, beliefs, institutions and behavioural patterns of the material in question. ${ }^{\text {xxiv }}$ Instead, the German Sex and the City aims for a desirable difference, both on a textual level, and in the sense of offering distinction and affirmation (as possessors of cultural capital) for those viewers 'desirably different enough' to master the fullness of the text. ${ }^{\mathrm{xxv}}$

That the Greek version reduces and the German version works to retain - even heighten - the Americanness of the source text further suggests something about these two languages and (television) cultures. In Greece, public discourse about the alleged impoverishment of the Greek language due to Anglicisms is coupled with a critical attitude towards US governments and, occasionally, toward US culture and television. Although hostility toward US culture is rarely expressed nowadays, the reduction of the Americanness of the text may work better for Greek television. Met with comparatively less public anxiety, especially as far as the younger demographic is concerned, the Anglicisation of the German language has increased in the last decade (overlapping, incidentally, with the timeframe of Sex and the City's transmission in Germany). Building on what Jan Pedersen has said about cultural interchangeability, ${ }^{\mathrm{xxv}}$ there may, due to the rise in globalisation and Anglicisation, simply be no need to find German-language equivalents for Sex and the City's references to US language and culture. However, the striking degree of this Americanness and the more obscure references mentioned above underline the notion of desirable difference, and mark the dubbed text with an American specificity that oddly draws more attention to itself than the same references would in the source text on US television. Interestingly enough, the German Sex and the City is arguably more defined (in terms of its meaning and status) by its Americanness than the US Sex and 
the City on US television, as the former's Americanness is more marked, standing out in contrast to something that is not American. It is on non-Anglophone television that the presence of English may take on additional meanings, in the case of German television, a signifier of 'trendiness'. xxvii

With their co-presence of German and English, and Greek and English, respectively, the dubbed and subtitled versions are marked by a complex composite, indeterminate and shifting German-American/Greek-American textuality. This potential of text/viewer to shift between the idiomatic German dub or Greek subtitles and English at any given moment renders the translatedness of these translated texts less transparent and highlights the inherent intertextuality and richness of dubbed and subtitled texts. ${ }^{\text {xxviii }}$

\section{Intertextuality $^{\text {xxix }}$}

In broadening the textual aesthetics focus, it is worth also considering intertextuality and the viewing experience offered by dubbed and subtitled texts. Traditional arguments concerning loss, lack and impoverishment hinge on the fact that the viewer does not receive the unmediated source text. However, this essay argues for the inherent (intertextual) richness of dubbed and subtitled texts and the different viewing experiences offered, based on the understanding that with both translation processes meaning is produced intertextually, through the co-presence of two texts: subtitled texts comprise of the whole of the audio-visual source text plus written text; and dubbed texts contain the source visuals and a target audio that largely replaces the source one. With subtitling, the co-presence of two texts is more easily recognisable, as the source text and subtitles are readily distinguishable. However, in each case, two texts are co-present and work together to produce - not necessarily intentionally, but perhaps inevitably - a sense of intertextuality. 
Subtitles work with the audio-visual co-text, ${ }^{\mathrm{xxx}}$ creating an inherent intertextuality: in Greece, ABC1 demographics, the main target audience for Sex and the City, are presumed to be conversant in English, at least to an intermediate level. Therefore, viewers may choose to ignore the subtitles. They may neither need nor wish for a translation. Or, they may choose to quickly read the subtitles 'ahead' of the audio-visual co-text, thus placing them in a position of knowledge, privilege and mastery, especially when subtitles appear before the dialogue begins. In the chosen extract, when Carrie walks into Susan-Sharon's apartment, Greek viewers can read

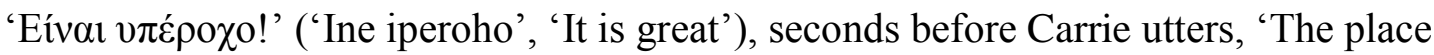
looks fantastic', thus anticipating her reaction. At any given moment, viewers may read the subtitles after listening to the audio-visual co-text, helping them catch anything that they may have missed (e.g. whispered dialogue, rapid or slurry delivery, or difficult accents/dialects). Subtitles in this context act as a form of 'safety net', which enables viewers to access to the fullness of the text. Whether they read the subtitles before or after listening to the audio-visual co-text, the viewers can place themselves in a position of mastery over the text. (This idea of mastery and control may be especially relevant to watching broadcast television, given the ephemeral quality of the live broadcast flow.)

Viewers also have the opportunity to think about the choices made in the translation process while reading the subtitles. This would include the choice of translated words or expression (such as the aforementioned 'grumpy'); but also the choices made in the condensation of spoken dialogue into written text, and the inherent judgements made in that decision in terms of what is important, what is retained, and what can be left out or reduced. As previously mentioned, with regards to the chosen 'The Awful Truth' extract, the reduction of swear words in the subtitles 
is potentially noticeable to viewers, and might even draw attention to absence and omission, which, in turn, defeats the purpose of the deletion. For target audiences conversant in English, the co-presence of the audio-visual source text and the subtitles creates a locus where meaning constantly shifts between these different texts and - to a greater or lesser extent - is produced intertextually. (Of course, in the case of Sex and the City, the source image frequently contains written text in the form of Carrie's column, and thus the subtitled Sex and the City contains two sets of on-screen written text. Therefore, the intertextuality of the subtitled Sex and the City is particularly complex.)

As far as the co-existence of two texts in dubbing practice is concerned, this version offers what must be recognised as a vocal performance. It consequently needs to find a place in scholarly work on performance and discussed using terminology of performance analysis: words such as tone, register, style, nuance or inflection. Dubbed texts offer two sets of performances (the source on-screen performance and the target vocal performance: see Table A) working together to create a sense of intertextuality. In both the dubbing voices cast and vocal performance given, it is evident that efforts are usually made to find a close match between the source text and the target one - but again, there are significant differences. Dubbing actor Irina von Bentheim provides Carrie's dubbed German voice. Von Bentheim has a deeper and more breathy delivery than Sarah Jessica Parker: one could even say, a 'deep-throat Carrie'. It is important to bear in mind that this is a deliberate choice, as von Bentheim's regular speaking voice sounds very different, and she offers a particular vocal performance for the role of Carrie, acting out the 'sexiness' of the part. Moreover, there are a numerous moments when the German vocal performance differs noticeably from the source text in terms of delivery, intonation and tone. For 
example, in the extract, Parker's delivery of the line 'Goodnight Grumpy' is arguably more provoking than von Bentheim's dubbed articulation of 'Gute Nacht Brummbär'. Later in the same episode, when Carrie's voice-over discusses 'spring-roll guy', the German dubbing is done tongue-in-cheek. A deliberately non-PC comedy Chinese accent is used to deliver the German for spring roll, 'Frühlingsrolle'. Other noticeable examples can be found in 'Critical Condition' (5: 6), when Carrie's voice-over reflects on Samantha Jones (Kim Cattrall) returning a faulty vibrator to the shop. The dubbed vocal performance incorporates imitating the vibrator's buzzing sound into the delivery of the narration voice-over. These differences in vocal performance are a deliberate choice made in the dubbing process; they are not suggested, implied or demanded by the source language version, and they frequently invest the German Sex and the City with a stronger degree of knowing playfulness in Carrie's narrating voice-over. $^{\text {xxxi }}$

However, dubbing does not only entail the co-presence of two texts; a more recognisable sense of intertextuality is created through the casting, specifically with the use of dubbing voices that are identifiable from other film and television shows (see Table B). As most dubbing actors in Germany voice a number of different (source text) actors, German audiences are likely to know and even recognise their voices (especially as many dubbing actors also perform on stage and screen). This raises an important issue concerned with the star persona of the voice; and how the actors, roles, texts and genres with which a dubbing voice is linked have a bearing upon the viewers' experience and interpretation of the text.

As the examples in Table B illustrate, any source text actor may be voiced by a number of different German dubbing actors. But once an actor becomes established, they tend to keep the same dubbing voice in film and television, and even across 
different media. For example, on German television, von Bentheim voices Parker not only in the series but also in hair care commercials fronted by the American actress. Consistency in dubbing casting can, however, depend on the availability of the dubbing actor, as well as the size of the role. Incidentally, German dubbing actors can sometimes gain fame as the voice of a particular actor: for example, von Bentheim has appeared on German chat shows talking about the HBO series, current attitudes towards sex and relationships, and has even given on-stage Sex and the City readings.

Casting the dubbing voice can also problematise the issue of intertextuality, Prior to his appearance as Mr. Big in Sex and the City, Chris Noth played Detective Mike Logan in the hit US crime series, Law \& Order (1990-2010). At this time Michael Schwarzmaier voiced him in the German dubbed version. Post-Sex and the City Noth played Detective Logan in the Law \& Order spin-off Criminal Intent (2001-present). But it is was not Schwarzmaier, but Thomas Vogt who now voiced him, the same dubbing actor used to voice Mr. Big. So, the two different voices preand post-Sex and the City for the same character problematise the intertextual relationship between franchise partners Law \& Order and Criminal Intent, while at the same time strengthening the intertextual links between Criminal Intent and Sex and the City.

Furthermore, as each source text actor is potentially voiced by a number of different dubbing voices, so each dubbing actor also voices a number of different source text actors (see Table C). For example, besides Parker, von Bentheim has in recent years voiced Anna Chancellor, Naomi Watts, Lara Flynn Boyle and Robin Wright, straddling film and television, different nationalities and a range of genres. Testament to the considerable skill, diversity and flexibility of dubbing actors, such intertextuality can invite or elicit a distracted, reflexive viewing experience, as 
audiences may recognise and even try to place the voice. However, given that Vogt is the designated voice for British actors Rupert Everett and Colin Firth, as well as African-American actor Laurence Fishburne, it raises further ethical issues deserving exploration beyond the scope of this essay. Argued here though is that dubbing is marked by an inherent intertextuality, a potentially infinite, vertical and horizontal web, in which different meanings, connotations and textual links are evoked that are not present nor even predicted in the source text, but are at the same time dependent on viewer knowledge and recognition.

The intertextuality of subtitling is more located within one text and centred on the interplay between the different, more easily distinguishable co-texts, while the intertextuality of dubbing is more located within the associations across different texts. As both dubbed and subtitled texts are marked by an inherent intertextual richness, offering complex viewing experiences, notions of loss and lack are, in turn, rendered far more problematic than previously suggested.

\section{Reflexive Slippage}

Our thoughts on intertextuality have already suggested that dubbed and subtitled texts offer complex viewing experiences. It is important to assert that both practices invite a consciously reflexive viewing experience and/or create the potential for reflexive moments of slippage for the viewer. As discussed, viewers of subtitled texts may shift between the different co-texts, while those of dubbed texts may recognise and even try to place the voices. In both cases, viewers may decide to play 'games' with the text, as it were, entering into a reflexive viewing experience. However, there is further potential for reflexive moments of slippage that go beyond these offered strategies, 
moments related to the suspension of disbelief conventionally required by both practices.

The use of subtitles creates this potential for reflexive moments of slippage, as viewers shifting between the audio-visual co-text and the subtitles may notice and reflect on gaps or points of tension between the two co-texts. Given the 'feedbackeffect $^{\text {xxxii }}$ from the source text, viewers may anticipate difficulties for the translation of puns and idiomatic expressions, like the ones previously discussed, or they may even speculate about how strong language will be handled in the subtitles. They may understand a word or expression and its connotations differently, or place a different emphasis on the dialogue/voice-over than the one given in the (frequently condensed) subtitles. This potential for reflexive moments of slippage occurs with dubbing when viewers may notice inconsistencies in lip-synchronisation, particularly during closeups, of especial importance to the television medium; or, maybe, even look out for those moments of slippage. In the chosen extract, for instance, there is a mismatch when Richard begins to shout at Susan-Sharon. Not wishing to overstate this, as audiences in dubbing countries are accustomed to dubbing and exercise a significant latitude as far as lip-synchronisation is concerned, but even with close lipsynchronisation, and even with closely related languages, such as German and English, there is still the potential for such reflexive moments of slippage. Furthermore, such slippages may occur more explicitly within the text when the source audio appears in the dubbed version. This is often the case with on-screen singing, and indeed, in 'The Man, The Myth, The Viagra' (2: 8), when Mr. Big sings, the dubbed version switches from Vogt's voice to Noth singing. This disruptive switch brings about a jolt in the viewing experience and (somewhat paradoxically) a sense of strangeness for German audiences unaccustomed to Noth's voice. 
With both practices, then, there is potential for reflexive slippage between the source and target text that may pull viewers out of their immersion in the frame of fiction and the required suspension of disbelief, and make them more aware of the audio-visual translation practices, which, in turn, become less transparent. Viewers may become more aware of the fact that what they are watching is not 'the (single) text', but only a version of it. With such potential moments of reflexive slippage, there is a double movement that the viewer may undergo, pulled out of the diegetic narrative while simultaneously drawn back towards the textuality of the text.

This reflexive slippage and double movement emerge in and through the presence of a number of different co-texts. So far the essay has distinguished between subtitling and dubbing on the basis that subtitling consists of co-texts that are more easily distinguishable from one another, while with dubbing, the co-texts are more likely to be experienced as one entity. With these moments of reflexive slippage, the co-presence of the source visuals and target audio becomes more noticeable. There is a sense of the source text 'coming through' at moments of slippage, a sense that there is another textual version 'beneath' the dubbed one, which moves the experience of viewing and listening to dubbed texts away from being whole and integrated, and brings dubbing closer to the more noticeable co-presence of distinguishable co-texts that usually marks subtitling. With Sex and the City, the sense of a co-presence of two co-texts with dubbing is brought more to the forefront by the pronounced Americanness of Sex and the City: the strong presence of references to US culture and English-language pronunciations defines the German Sex and the City with an indeterminate, both US and German textuality that makes the dubbing less transparent, emphasising the foreignness and underlying presence of the source text and thus highlighting the translatedness and constructedness of the target text. 
With subtitling, what further marks these moments of reflexive slippage is that viewers are situated between two different discourses (written and oral) and different temporal structures, which allows viewers to move between and across these. Such shift concerns the significance of the difference in syntax between oral and written discourse. While the oral dialogue is based on a written text (the script), it is also characterised by the spontaneity, incompleteness and presentness of the spoken. In the Greek subtitling of the chosen Sex and the City extract, there are moments where the written approximates the verbal: Susan-Sharon's plea to Richard, 'I know, it's just

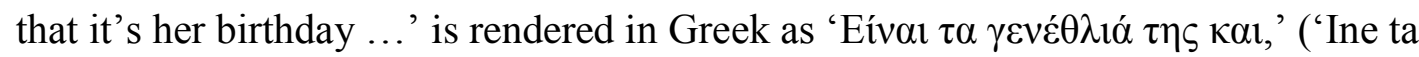
genethlia tis ke'), which back-translates as 'It's her birthday, and,'. This condensation gives the impression of an unfinished sentence through the use of the word 'and' which is not in the source audio and therefore a deliberate addition - followed by a comma, which reinforces the suddenness of Richard's outburst. Similarly, 'Carrie had this idea about returning’ becomes 'H Kápv cíxe...' ('I Carrie ihe...’), which backtranslates as simply 'Carrie had...'. Here, the use of punctuation as a paralinguistic sign of interruption ${ }^{\text {xxxii }}$ and the incompleteness of the sentence retain the quick fragmented quality of the verbal.

On the other hand, subtitling inevitably adapts the oral into a written discourse, with the latter's stricter, more orderly syntax. For example, interjections such as Susan-Sharon's 'Okay, you know what,' does not appear in the Greek subtitles. It moves the Greek target text away from the incomplete, spontaneous, open and unfinished quality of the source text towards a more final, thought-out, fixed and complete quality. This opens up further potential for (reflexive) slippage for the viewer, who can shift between the spontaneous presentness and immediacy of the oral dialogue and the more finalised pastness (and, in some way, both practically and 
conceptually, the hindsight) of the subtitles. Amir Hassanpour argues that, 'Unlike oral communication, which is usually dialogic and participatory, written language separates the writer and the reader in space and time. ${ }^{\text {xxxiv }}$ Following this line of thought, viewers of subtitles may shift between different temporalities and reflexively step away from the evolving 'here and now' of the diegesis, as the subtitles are a subtle reminder of post-production processes that took place in the past.

Reflexive moments of slippage related to dubbing may produce a similar alienating effect, although the oral performances of dubbing actors provide a stronger sense of presentness. With both practices, reflexive moments of slippage highlight inherent tensions within the co-presence of different co-texts and therefore address and problematise the internalised 'contract of illusion', ${ }^{\mathrm{xxv}}$ bringing out the instability and tension that mark the required conventional suspension of disbelief.

\section{Conclusion}

Far from being defined by necessity, practicality and constraint, dubbing and subtitling must be understood as transformative practices. Not only do they significantly contribute to determining the meaning of the target text, but they problematise notions of a fixed, stable core of textual identity: the idea that, when scheduling, promotion, for example, are taken out of the equation, there is still somehow the same core of the text there - the "program proper' ${ }^{\text {xxxvi }}$ - which often underlies thinking about television and television drama. Through an unstable copresence of different co-texts, dubbing and subtitling offer different viewing positions and experiences to audiences. These inherently intertextual and reflexive experiences are not recognised enough in work on globally circulated television texts and/or work on audiences. 
Having only begun to scratch the surface, this essay indicates the need for further work on audio-visual translation practices, which have a bearing on a significant number of more established fields of enquiry within the study of television (and, indeed, film), such as performance, audiences, institutions, globalisation, aesthetics and close textual analysis. Further research could focus on developing the methodology for the analysis of vocal performances; the ways in which a vocal performance can relate to the visual performance of a different actor; institutional recontextualisation of texts and new textual identities; audiences' perception of textual identities in different countries and institutional contexts; and translation and its relation to ideology. Most of these topics offer the opportunity for interdisciplinary research, connecting performance studies and television studies or translation and close analysis of audiovisual texts. Links between academic research and professional practices, such as translation, dubbing and subtitling, as well as casting, importing, advertising and scheduling programmes, could be developed. In any case, it is essential to move away from arguments of 'correctness' and/or 'equivalence' and towards a more complex discussion of the creative choices involved in dubbing and subtitling. As this essay demonstrates, there is in fact no one Sex and the City, but only Sex and the Cities.

\section{Acknowledgments}

We would like to thank Iman Khonji, Jens Schwarz and Dr. Mark Broughton for their helpful comments on drafts of this essay. We would also like to thank Alter for the information they have given us on the version of subtitles that they used. 


\section{Appendix}

Table A

\begin{tabular}{|l|l|l|}
\hline Sex and the City character & Source Text (ST) Actor & $\begin{array}{c}\text { German Target Text (TT) } \\
\text { Actor }\end{array}$ \\
\hline Carrie Bradshaw & Sarah Jessica Parker & Irina von Bentheim \\
\hline Samantha Jones & Kim Cattrall & Katarina Tomaschewsky \\
\hline Charlotte York & Kristin Davis & Gundi Eberhard \\
\hline Miranda Hobbes & Cynthia Nixon & Marina Krogull \\
\hline Mr. Big & Chris Noth & Thomas Vogt \\
\hline
\end{tabular}

Two sets of performers and performances in the German dubbed Sex and the City. Note: This information has been compiled using data from the Synchronkartei, available online at http://www.synchronkartei.de.

Table B

\begin{tabular}{|c|c|}
\hline ST Actor & $\begin{array}{l}\text { German TT Actors (chronological order; } \\
\text { selection only) }\end{array}$ \\
\hline Sarah Jessica Parker & $\begin{array}{l}\text { - Katharina Gräfe in L.A. Story } \\
\text { (1990) } \\
\text { - Christine Scherer in Ed Wood } \\
\text { (1994) } \\
\text { - Melanie Pukaß in Mars Attacks! } \\
\text { (1996) } \\
\text { - Irina von Bentheim in Sex and the } \\
\text { City (1998-2004) } \\
\text { - Melanie Pukaß in Dudley Do- } \\
\text { Right (1999) } \\
\text { Irina von Bentheim in The Family } \\
\text { Stone (2005) }\end{array}$ \\
\hline Kim Cattrall & $\begin{array}{l}\text { - } \text { Carolin van Bergen in Columbo: } \\
\text { - } \quad \text { Susanna Bial a Murder (1978) } \\
\text { Academy (1984) } \\
\text { - Simone Brahmann in Big Trouble } \\
\text { in Little China_(1986) } \\
\text { - Simone Brahmann in The Return } \\
\text { of the Musketeers (1989) } \\
\text { - Katharina Lopinski in Star Trek } \\
\text { VI: The Undiscovered Country } \\
\text { (1991) } \\
\text { Maud Ackermann in Star Trek VI: } \\
\text { The Undiscovered Country } \\
\text { (1991) [new scenes] }\end{array}$ \\
\hline
\end{tabular}




\begin{tabular}{|c|c|}
\hline & $\begin{array}{l}\text { - Katarina Tomaschewsky in Sex } \\
\text { and the City (1998-2004) } \\
\text { - Katarina Tomaschewsky in Ice } \\
\text { Princess (2005) }\end{array}$ \\
\hline Kristin Davis & $\begin{array}{l}\text { - Gundi Eberhard in Friends } \\
\text { (2000) } \\
\text { - Gundi Eberhard in The Shaggy } \\
\text { Dog (2006) }\end{array}$ \\
\hline Cynthia Nixon & 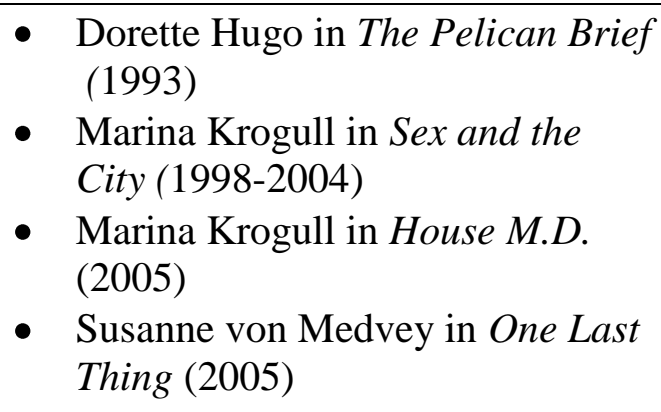 \\
\hline Chris Noth & 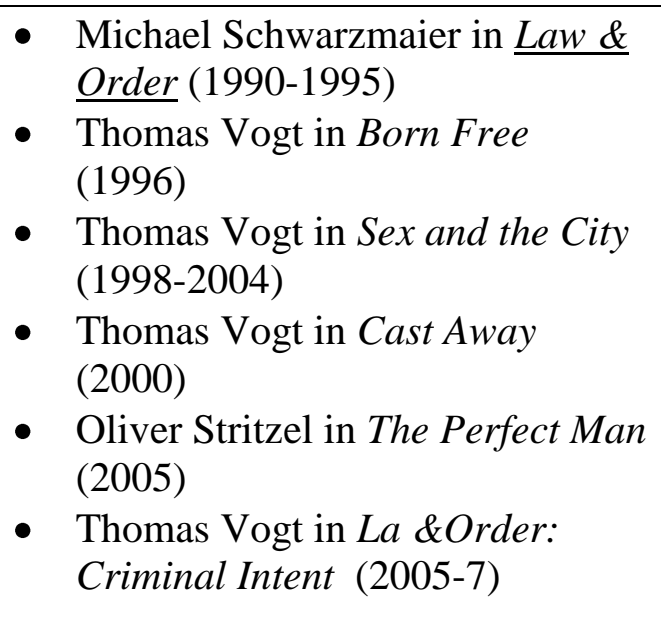 \\
\hline Sarah Jessica Parker & $\begin{array}{l}\text { - Katharina Gräfe in L.A. Story } \\
\text { (1990) } \\
\text { - Christine Scherer in Ed Wood } \\
\text { (1994) } \\
\text { - Melanie Pukaß in Mars Attacks! } \\
\text { (1996) } \\
\text { - Irina von Bentheim in Sex and the } \\
\text { City (1998-2004) } \\
\text { - Melanie Pukaß in Dudley Do- } \\
\text { Right (1999) } \\
\text { - Irina von Bentheim in The Family } \\
\text { Stone (2005) }\end{array}$ \\
\hline
\end{tabular}

Intertextual relationships of the vocal star persona (1): links from the ST actor to multiple dubbing actors. 
TABLE c

\begin{tabular}{|c|c|c|}
\hline German TT Actor & ST Actor (selection only) & Texts \\
\hline \multirow[t]{8}{*}{ Irina von Bentheim } & Lisa Bonet & High Fidelity (2000) \\
\hline & Anna Chancellor & What a Girl Wants (2003) \\
\hline & Minnie Driver & $\begin{array}{l}\text { Grosse Pointe Blank } \\
\text { (1997) }\end{array}$ \\
\hline & Jennifer Esposito & $\begin{array}{l}\text { I Still Know What You Did } \\
\text { Last Summer (1998) }\end{array}$ \\
\hline & Lara Flynn Boyle & The Practice (1997-2004) \\
\hline & Sarah Jessica Parker & $\begin{array}{l}\text { Sex and the City (1998- } \\
\text { 2004), The Family Stone } \\
(2005)\end{array}$ \\
\hline & Naomi Watts & $\begin{array}{l}\text { Mulholland Drive (2001), } \\
\text { The Ring (2002), } 21 \\
\text { Grams (2003) }\end{array}$ \\
\hline & Robin Wright & $\begin{array}{l}\text { Forrest Gump (1994), } \\
\text { Empire Falls (2005) }\end{array}$ \\
\hline \multirow[t]{2}{*}{ Katarina Tomaschewsky } & Kim Cattrall & $\begin{array}{l}\text { Sex and the City (1998- } \\
\text { 2004) }\end{array}$ \\
\hline & Jorja Fox & $\begin{array}{l}\text { E.R. (1996-1999) and CSI } \\
\text { (2000-present) }\end{array}$ \\
\hline \multirow[t]{3}{*}{ Gundi Eberhard } & Dana Delany & $\begin{array}{l}\text { Desperate Housewives } \\
\text { (2007-present) }\end{array}$ \\
\hline & Kristin Davis & $\begin{array}{l}\text { Sex and the City (1998- } \\
\text { 2004) and Friends (2000) }\end{array}$ \\
\hline & Mercedes McNab & $\begin{array}{l}\text { Buffy the Vampire Slayer } \\
(1997-2001) \text { and Angel } \\
(2001-4)\end{array}$ \\
\hline \multirow[t]{6}{*}{ Marina Krogull } & Jayne Brook & $\begin{array}{l}\text { Chicago Hope (1995- } \\
\text { 1999) }\end{array}$ \\
\hline & Holly Hunter & $\begin{array}{l}\text { The Piano (1993) and The } \\
\text { Firm_(1993) }\end{array}$ \\
\hline & Sofia Milos & CSI: Miami (2003-present) \\
\hline & Marilyn Monroe & $\begin{array}{l}\text { in Don't Bother to Knock } \\
\text { (1952) [second dub] }\end{array}$ \\
\hline & Cynthia Nixon & $\begin{array}{l}\text { Sex and the City (1998- } \\
\text { 2004) and House M.D. } \\
(2004)\end{array}$ \\
\hline & Amanda Plummer & $\begin{array}{l}\text { The Fisher King (1991) } \\
\text { and Pulp Fiction (1994) }\end{array}$ \\
\hline \multirow[t]{2}{*}{ Thomas Vogt } & Rupert Everett & $\begin{array}{l}\text { My Best Friend's Wedding } \\
\text { (1997), An Ideal Husband } \\
\text { (1999), Shrek } 2 \text { (2004), } \\
\text { Shrek the Third_(2007) }\end{array}$ \\
\hline & Colin Firth & $\begin{array}{l}\text { Bridget Jones's Diary } \\
\text { (2001), Girl with a Pearl } \\
\text { Earring (2003), Love }\end{array}$ \\
\hline
\end{tabular}




\begin{tabular}{|l|l|l|}
\hline & & $\begin{array}{l}\text { Actually (2003), Bridget } \\
\text { Jones: The Edge of Reason } \\
(2004)\end{array}$ \\
\hline & Laurence Fishburne & $\begin{array}{l}\text { The Matrix (1999), The } \\
\text { Matrix Reloaded (2003), } \\
\text { The Matrix Revolutions } \\
\text { (2003), Bobby (2006) }\end{array}$ \\
\hline & Costas Mandylor & $\begin{array}{l}\text { Sex and the City (1998- } \\
\text { 2004) }\end{array}$ \\
\hline & Chris Noth & $\begin{array}{l}\text { My Best Friend's Wedding } \\
(1997), \text { An Ideal Husband } \\
(1999), \text { Shrek 2 (2004), } \\
\text { Shrek the Third (2007) }\end{array}$ \\
\hline
\end{tabular}

Intertextual relationships of the vocal star persona (2): links from the dubbing actor to multiple ST actors.

${ }^{\text {i }}$ See Richard Kilborn, "“Speak my Language”: Current Attitudes to Television Subtitling and Dubbing,' Media, Culture and Society, 15, 1993, 641-60. Subtitling usually inspires less contempt because of its association with art cinema and documentary, and the view that 'the presence of the original soundtrack acts as a form of guarantee of authenticity.' Ibid., 643.

ii See, Amir Hassanpour, 'Subtitling,' The Encyclopedia of Television, 1997; http://www.museum.tv/archives/etv/S/htmlS/subtitling/subtitling.htm, accessed 13 October 2010.

${ }^{\text {iii }}$ Hassanpour suggests that dubbing should be understood 'as an activity involving a recreation of the original text'. Amir Hassanpour, 'Dubbing,' The Encyclopedia of Television, 1997; http://www.museum.tv/archives/etv/D/htmlD/dubbing/dubbing.htm, accessed 13 October 2010.

iv Hassanpour, 'Dubbing.'

' John Gibbs, 'Filmmakers' Choices,' in John Gibbs and Douglas Pye, eds, Close-Up

1: Filmmakers' Choices, The Pop Song in Film, Reading Buffy, Wallflower, 2006, p. 5 .

${ }^{\text {vi }}$ See Herbert Schiller, 'Transnational Media and National Development,' in Kaarle Nordenstreng and Herbert Schiller, eds, National Sovereignty and International Communication, Ablex, 1979, p. 21-23.

${ }^{v i i}$ Astrid Henry, 'Orgasms and Empowerment: Sex and the City and the Third Wave Feminism,' in Kim Akass and Janet McCabe, eds, Reading Sex and the City: Critical Approaches, I.B. Tauris, 2004, p. 66.

viii As Tony Kelso argues: 'If it relies on millions of everyday viewers to relinquish a few extra dollars each month for the opportunity to view programming they cannot get on commercial TV, then HBO simply must continuously distinguish itself from broadcast and basic cable stations if it hopes to remain viable.' Kelso, 'And Now No Word from Our Sponsor: How HBO Puts the Risk Back into Television,' in Marc Leverette, Brian Ott and Cara Buckley, eds, It's Not TV: Watching HBO in the PostTelevision Era, Routledge, 2008, p. 49.

${ }^{\text {ix }}$ Although we cannot expand on this issue in the limited space of this essay, there are interesting links here to Catherine Johnson's work on tele-branding, and how 
programmes function as brands. See Catherine Johnson, 'Tele-branding in TVIII: The Network as Brand and the Programme as Brand,' New Review of Film and Television Studies, 5, 1, 2007, 5-24.

${ }^{\mathrm{x}}$ For further details, see Marina Antonioni, 'Sexuelle Zumutungen,' Der Spiegel, 19 July 2006, p. 42.

${ }^{x i}$ NCRTV/E 2 P, decision no. 24, 27 January 2004; http://www.esr.gr/arxeion$\mathrm{xml} /$ pages/esr/esrSite/file-get?arx-files-disposition=attachment\&arx-files-entry$\mathrm{id}=9 \mathrm{ec} 20 \mathrm{fd} 85 \mathrm{~b} 1 \mathrm{c} 1 \mathrm{e} 7983571826 \mathrm{e} 98263 \mathrm{e} 5$, accessed on 13 October 2010.

${ }^{x i i}$ According to Greek legislation, television channels cannot broadcast anything that may 'damage the spiritual and moral growth of the underage public'. (art. 8, par. 1, P.D. 100/2000: authors' translation). In NCRTV/ E $\Sigma$ P's decision mentioned above, it is noted that there was a disagreement as to whether sexually explicit dialogue in a comedy can be spiritually harmful to the underage public. These arguments open up a very interesting discussion on humour and sexual explicitness, which we hope to pick up in future work.

xiii Sex and the City also exists in a 'tamed' version within the US syndication market, which further underlines the importance of our emphasis on the instability of textual identity. Entertainment Weekly reports: 'Sex's producers have said that they always filmed alternate, less racy takes of the show's more eyebrow-raising moments with the eventual syndication of the show in mind.' (Gary Susman, 'City Slicker,' Entertainment Weekly, 30 September 2003, p. 24) Furthermore, we wish to note that we are working with the DVD subtitles, which to a significant amount of Greek viewers represent the first and lasting experience of the text, as successful US series are released on DVD roughly at the same time as they become available on free-to-air television. In addition, Alter, the first free-to-air channel (and thus available to all Greek viewers) to broadcast the series, used the same subtitles. The presence of multiple versions of Sex and the City on Greek television further suggests that our emphasis on the instability of textual identity also, of course, applies to audio-visual translation practices.

${ }^{x i v}$ Deborah Jermyn, Sex and the City, TV Milestones Series, Wayne State University Press, 2009, p. 47.

${ }^{\mathrm{xv}}$ Frederic Chaume, 'Film Studies and Translation Studies: Two Disciplines at Stake in Audiovisual Translation,' Meta: Journal des Traducteurs/Meta: Translators' Journal, 49, 1, 2004, 20.

${ }^{\mathrm{xvi}}$ Jonathan Bignell, 'Sex, Confession and Witness' in Akass and McCabe, eds, Reading Sex and the City, pp. 161-76.

xvii Joanna di Mattia, 'What's the Harm in Believing?': Mr Big, Mr Perfect, and the Romantic Quest for Sex and the City's Mr Right,' in Akass and McCabe, eds, Reading Sex and the City, p. 17.

xviii Jan Pedersen, 'Cultural Interchangeability: The Effects of Substituting Cultural References in Subtitling,' Perspectives: Studies in Translatology, 15, 1, 2007, 30-1. xix Ibid., 31.

${ }^{\mathrm{xx}}$ See ibid., 39.

${ }^{x x i}$ Ibid., 40; emphasis in original.

xxii For example, in the episode 'Evolution' (2:11), when the four protagonists discuss being comfortable enough to 'do a number two' at a partner's place, Samantha's joke about Charlotte being 'so uptight you need to do a number seven' is rendered as 'so verklemmt wie du bist, lässt du's dir wohl lieber wegoperieren' - which approximates to her being so uptight that she should have it surgically removed. 
xxiii For example, in the episode 'Take Me Out to the Ballgame' (2: 1), 'batting average' is rendered as 'batting average', when it could have been presented as 'batting Durchschnitt'.

${ }^{\text {xxiv }}$ Colin Hoskins and Rolf Mirus, 'Reasons for the US Dominance of the International Trade in Television Programmes,' Media, Culture \& Society, 10, 4, 1988, 500. Interestingly enough, their argument continues as follows: 'Included in the cultural discount are reductions in appreciation due to dubbing and subtitling.' Ibid. ${ }^{\mathrm{xxv}}$ This sense of exclusivity, of limited access to the text (albeit access of a different kind) is reminiscent of the source text on HBO.

${ }^{x x v i}$ Pedersen, 'Cultural Interchangeability', 30-48.

xxvii This is further evident on an institutional/industrial level: ProSieben's current channel tagline is: 'We love to entertain you.'

xxviii Interestingly, if we accept that viewers tacitly agree to a willing suspension of disbelief and accept that subtitles and the dubbed voices are the dialogue (see Pedersen, 'Cultural Interchangeability', 40), both retaining the US references within a largely German-language target text and reducing them in the Greek subtitles break the illusion and cause reflexive moments of slippage, a point to which we will return. ${ }^{x x i x}$ We use 'intertextuality' instead of making the finer distinction between intratextuality and intertextuality to emphasise the distinctness of the different components of the subtitled audiovisual text.

${ }^{\mathrm{xxx}}$ Pettit discusses how the use of subtitles may be influenced by the use of audiovisual forms. See Zoë Pettit, 'The Audio-Visual Text: Subtitling and Dubbing Different Genres,' Meta, 49, 1, 2004, 25-38.

${ }^{x x x i}$ Whilst it is true that changing the performance of the voice-over narration is easier, in the sense that there is less need for concern with a mismatch with the onscreen physical/bodily performance, the very deliberate, conscious change of tone in the narration is striking.

${ }^{\text {xxxii }}$ Henrik Gottlieb, Subtitles, Translation \& Idioms, Centre for Translation Studies, University of Copenhagen, 1997, p. 93.

xxxiii See Chaume, 'Film Studies and Translation Studies', 12-24.

xxxiv Amir Hassanpour, 'Language and Television,' The Encyclopedia of Television, 1997; http://www.museum.tv/archives/etv/L/htmlL/languageand/languangeand.htm, accessed 13 October 2010.

${ }^{\mathrm{xxxv}}$ Pedersen, 'Cultural Interchangeability,' 40.

${ }^{x x x v i}$ See Jostein Gripsrud, The Dynasty Years: Hollywood Television and Critical Media Studies, Routledge, 1995, pp. 131-33. 